\title{
PENYUSUNAN LEMBAR KERJA PESERTA DIDIK (LKPD) BIOLOGI SMA MELALUI INVENTARISASI TUMBUHAN YANG BERPOTENSI ATAU SEBAGAI PEWARNA ALAMI DI KOTA METRO
}

\author{
Rasuane Noor \\ Pendidikan Biologi FKIP Universitas Muhammadiyah Metro \\ E-mail: rasuanenoor@gmail.com
}

\begin{abstract}
Worksheet Students serve as guides learners and also allows learners and teachers to conduct classes. Worksheet Students drafting high school biology on biodiversity, through the inventory of plants that could potentially or as a natural staining in the city's Metro is very important to provide information and interesting and more contextual with the situation, the condition of school or social environment of students in the city's Metro. The aim of research in preparation Worksheet-based Scientific Approach Students are expected later able to become one of the means to improve students' understanding of and ability to think on the matter of biodiversity.
\end{abstract}

Potential plant species or as a natural staining in Metro city found as many as 52 species were planted scattered in various districts. Society in general, grow crops and use natural staining for coloring food. The parts used are the roots, stems, leaves and flowers. Usually, these natural staining can be obtained from plants that have bright colors and typical of these plants. Results of research on plants that potentially or as a natural staining in the city's Metro is structured as a plan of learning resources Worksheet Students high school biology-based Scientific Approach and based validation state that Worksheet Students theoretically have criteria strong and can be used as a learning resource of biological material biodiversity.

Kata Kunci: tu mbuhan pewarna alami, Worksheet Students

Kegiatan belajar mengajar merupakan suatu proses tidak terlepas dengan sumber belajar. Sumber belajar merupakan segala sesuatu dan dengan mana seseorang mempelajari sesuatu meliputi: pesan, orang, bahan, alat, teknik, dan latar. Sumber belajar dapat diperoleh dimana saja dan kapan saja. Sumber belajar mempunyai peran yang sangat erat dengan pembelajaran yang dilakukan, dan pola-pola yang dilakukan oleh guru (Karwono dan Mularsih, 2012). Sumber belajar nantinya digunakan oleh peserta didik sebagai titik awal dalam membangun pemahaman sebuah tujuan dalam kegiatan pembelajaran.
Kegiatan belajar nantinya diharapkan akan mampu merubah seseorang dari keadaan tidak tahu menjadi tahu, dari tidak mengerti menjadi mengerti, dan yang lebih penting lagi dari keadaan tidak paham menjadi paham. Kegiatan belajar mengajar memiliki ciri-ciri diantaranya: terjadi perubahan aktual maupun potensial pada diri individu yang belajar, perubahan diperoleh karena usaha dan perjuangan, dan perubahan didapat karena kemampuan baru yang berlangsung relatif lama (Sunaryo, 2002). 
$2013 \begin{array}{rr}\text { Pembelajaran } \\ \text { menekankan }\end{array}$ pembelajaran dengan pendekatan ilmiah (Scientific Approach) yang dimaksudkan memberikan pemahaman kepada siswa dalam mengamati, menanya, menalar, mencoba, dan membentuk jejaring. Kurikulum 2013 lebih menekankan/mengarahkan seorang guru mampu mengelola pembelajaran yang bermutu sehingga dapat menyajikan pembelajaran yang menarik, kreatif, menantang, dan menyenangkan bagi siswa.

Sumber belajar biologi berupa LKS yang memuat ringkasan materi, dan latihan soal yang kurang variatif sehingga menyebabkan kemampuan siswa kurang terasah. Upaya yang dapat dilakukan untuk memperbaiki pemahaman dan kemampuan berpikir siswa yaitu dengan diciptakannya suatu sumber belajar yang mendukung upaya perbaikan tersebut. Salah satu sumber belajar yang sekarang dikembangkan tersebut adalah LKPD (Lembar Kerja Peserta Didik).

Lembar Kerja Peserta Didik (LKPD) berfungsi sebagai panduan belajar peserta didik dan juga memudahkan peserta didik dan guru melakukan kegiatan belajar mengajar. LKPD disusun menggunakan beberapa kriteria yang tujuannya yaitu untuk menarik siswa agar lebih aktif dalam proses pembelajaran. Penyusunan LKPD dapat meliputi beberapa unsur yang harus ada didalamnya. Penggunaan unsur-unsur tersebut tergantung dari pengembang yang akan menggunakannya seperti judul, kompetensi dasar, informasi pendukung, tugas atau langkah kerja, dan penilaian. Widyantini (2013), dan Prastowo (2012). LKPD bisa dibuat sendiri oleh guru yang bersangkutan. Sehingga lebih menarik serta lebih kontekstual dengan situasi dan kondisi sekolah atau pun lingkungan sosial peserta didik. Peserta didik agar secara aktif terlibat dalam materi, maka dibutuhkan sebuah metode dalam penyusunan LKPD tersebut. Salah satu metode yang bisa diterapkan untuk mendapatkan hasil yang optimal dari pemanfaatan LKPD yaitu metode 'SQ4R' atau Survey, Question, Read, Reflect, Recites, and Review (menyurvei, membuat pertanyaan, membaca, mengikuti, meringkas, dan mengulang) Prastowo (2012).

Materi yang dipelajari di sekolah salah satunya adalah Keanekaragaman Hayati. Berdasarkan Indrawan (2007) Keanekaragaman hayati merupakan sumber daya alternatif bagi manusia yang digolongkan menjadi 3 tingkatan yaitu: keanekaragaman spesies, keanekaragman genetik, dan keanekaragaman komunitas. Keanekargaman spesies menggambarkan seluruh cakupan adaptasi ekologi, serta menggambarkan evolusi spesies terhadap lingkungan tertentu.

Indonesia memiliki keanekaragaman flora dan fauna yang tinggi. Agenda 21 mengenai peningkatan keanekaragaman hayati, hemat energi, dan mengatasi masalah lingkungan serta undang-undang nomor 5 tahun 1990, tentang konservasi sumberdaya alam hayati, ekosistemnya serta World Conservation Strategy, maka keberadaan dan kelestarian flora di suatu daerah merupakan komponen penting dalam pembangunan wilayah. Melalui inventarisasi tumbuhan yang berpotensi atau sebagai pewarna alami merupakan salah satu andil dalam menyuk seskan tujuan konservatif tersebut. 
Pewarna alami adalah suatu zat warna tertentu yang dapat digunakan untuk mewarnai, biasanya pewarna alam digunakan untuk pewarna makanan maupun sebagai pewarna alternatif jaringan. Biasanya pewarna alami diperoleh dari tumbuhan yang memiliki warna cerah sehingga dapat digunakan untuk proses pewarnaan. Bahan pewarna dari alam dapat diperoleh dari proses ekstraksi bagian-bagian tanaman seperti buah, biji, daun, kulit kayu, atau kelopak bunga Wismaji dkk (2010). Tumbuhan tumbuhan yang sudah biasa digunakan untuk pewarna alami meliputi: jati, pandan wangi, buah naga, tarum, pinang, bunga kumakuma, kunyit, suji, kulit buah manggis, angsana, buah bit, kesumba, akar mengkudu, secang, bunga telang, cabe merah, rosella, ubi ungu, wortel, akar harendong, biji jelawe, jambu mete, buah muda rambutan, kembang sepatu, bunga sri gading, bunga tembelekan, daun gambir, daun indigo, daun jambu biji, daun mangga, daun pulutan, daun putri malu, alpukat, kenari, kulit jengkol, mundu, pinus, sedar merah, ulin, senggani,puring, pacar kuku, pacar air, nangka, ketepeng kebo, kenikir hias, kulit kelapa, kakoa, kecombrang, belimbing sayur, ketapang, soga, strowberry, lemon, nanas, teh, anggur, tomat,bunga kana/tasbih,krisan, daun katuk, bawang merah, angkak, kluwak/pucung, karamel dan gula jawa. Di masyarakat pewarna alami digunakan untuk mewarnai makanan dan mewarnai benda-benda kerajinan masyarakat, selain itu pewarna alami digunakan untuk mewarnai suatu preparat tertentu.

Berkembangnya teknologi saat ini sehingga banyak manfaatkan pewarna dari bahan sintesis yang dibuat oleh pabrik kimia untuk kebutuhan pewarna makanan maupun pengamatan jaringan. Pemanfaatan zat pewarna alami sudah mulai bergeser dengan menggunakan zat pewarna sintetis. Akan tetapi bahan-bahan sintesis tersebut memiliki efek negatif yaitu harganya mahal dan bersifat karsinogenik. Zat karsinogenik dalam pewarna sintetis dapat menimbulkan masalah bagi lingkungan dan kesehatan manusia. Oleh karena itu zat warna sintetis perlu diganti menggunakan zat pewarna alami untuk mengurangi masalah yang ditimbulkan.

Kota Metro dengan selogan kota pendidikan berupaya menjadikan wilayahnya menjadi media pembelajaran bagi masyarakatnya senergi dengan kerangka pembangunan berkelanjutan dibidang pendidikan yaitu yang menanamkan konsep pemanfaatan dan pelestarian keanekaragaman hayati. Tata ruang Kota Metro umumnya perumahan, perkantoran dan lahan pertanian, perumahan masih mempunyai pekarangan yang cukup luas. Di sekitar rumah penduduk terutama di daerah pedesaan, yang belum banyak dimanfaatkan secara ekonomis. Adanya ancaman punahnya tumbuhan terutama disebabkan kerusakan habitat yaitu kegiatan eksploitasi, perluasan lahan perumahan, areal wisata dan keperluan pembangunan. Kegiatan tersebut secara langsung maupun tidak langsung dapat menyebabkan kelangkaan dan punahnya spesies yang terdapat di suatu wilayah. Disamping itu erosi, hilangnya budaya dan pengetahuan tradisional dari penduduk lokal tentang pemanfaatan tumbuhan perlu dikaji secara mendalam, sehingga flora 
yang sudah ada disuatu daerah tetap terjaga kelestariannya.

Penyusunan lembar kerja peserta didik (LKPD) biologi SMA pada keanekaragaman hayati, melalui inventarisasi tumbuhan yang berpotensi atau sebagai pewarna alami di kota Metro sangat penting dilakukan untuk memberikan informasi dan menarik serta lebih kontekstual dengan situasi, kondisi sekolah atau pun lingkungan sosial peserta didik di kota Metro. Hasil penelitian ini nantinya diharapkan dapat menjadi salah satu sumber belajar siswa tentang materi keanekaragaman hayati. Maka peneliti ingin membuat LKPD berbasis pendekatan ilmiah (Scientific Approach) dari hasil penelitiannya. LKPD ini diharapkan nantinya mampu menjadi salah satu sarana untuk memperbaiki pemahaman dan kemampuan berpikir siswa.

\section{METODE}

Penelitian ini dilakukan di seluruh kecamatan Kota Metro, meliputi areal pekarangan, jalan, lahan kosong dan areal flora yang termasuk kawasan Ruang Terbuka Hijau. Penelitian meliputi arah jalan utama 5 kecamatan Kota Metro, yaitu Metro Pusat, Metro Barat, Metro Timur, Metro Utara, dan Metro Selatan. Waktu penelitian dilaksanakan dari bulan Januari 2014 - Maret 2014. Pengumpulan data dilakukan melalui observasi langsung di lapangan untuk mendapatkan tanaman tumbuhan yang berpotensi atau sebagai pewarna alami kemudian diinventarisasi, Identifikasi, Studi Literatur meliputi: nama lokal, nama ilmiah, nama famili dan deskripsi morfologinya mendata tumbuhan di kecamatan Kota Metro.

\section{Analisis Sumber Belajar LKPD}

Analisis sumber belajar LKPD dilakukan setelah validasi. Hasil validasi ini menentukan tingkat kelayakan sumber belajar LKPD jika nantinya digunakan peserta didik dalam proses pembelajaran. LKPD yang dibuat akan divalidasi oleh tim validator berdasarkan beberapa aspek identitas LKPD, tampilan atau teknis, bahasa/konstruksi dan isi. Penilaian isi meliputi kesesuaian materi dengan konsep serta pemilihan materi sesuai dengan indikator dan tujuan pembelajaran. Tehnik analisis data pada validasi LKPD dilakukan dengan menggunakan angket yang diberikan kepada para ahli validator. Menurut Arikunto (2010) secara garis besar, pekerjaan analisis data meliputi 3 langkah sebagai berikut: persiapan analisis data produk, tabulasi analisis data produk, dan penerapan analisis data produk. Penerapan analisis data yaitu untuk melihat kelayakan sumber belajar LKPD sesuai sengan hasil persentase.

Penghitungan kelayakan LKPD dapat dilakukan dengan menggunakan rumus persentase kelayakan. Puspitadewi (2014) menyatakan persentase kelayakan lembar kegiatan peserta didik (LKPD) dapat digunakan rumus sebagai berikut:

Nilai kelay akan $=\frac{\sum \text { skor semua aspek dari semua validator }}{\text { skormaksimal semua aspek }} \times 100 \%$

Berdasarkan persentase hasil validasi yang telah diperoleh kemudian ditransformasikan ke dalam tabel supaya pembacaan hasil penelitian menjadi mudah, maka dalam menentukan kriteria kualitatif 
tersebut dilakukan dengan cara

berikut:

melihat Tabel 4. yaitu sebagai

Tabel 1. Persentase dan Kriteria Penilaian Lembar Kegiatan Peserta Didik

\begin{tabular}{|l|l|l|}
\hline NO & Persentase & Kriteria \\
\hline 1 & $0 \%-20 \%$ & Sangat Kurang \\
\hline 2 & $21 \%-40 \%$ & Kurang \\
\hline 3 & $41 \%-60 \%$ & Cukup \\
\hline 4 & $61 \%-80 \%$ & Kuat \\
\hline 5 & $81 \%-100 \%$ & Sangat Kuat \\
\hline
\end{tabular}

Sumber: (Fahrucah dan Sugiyanto, 2012)

HASIL DAN PEMBAHASAN

\section{A. Hasil}

Inventarisasi tumbuhan pewarna alami yang ada di Kota Metro yang dilakukan selama 2 bulan didapatkan 52 spesies tumbuhan. Serta distribusi hampir merata di seluruh Kecamatan di Kota Metro. Hasil pengamatan inventarisasi tumbuhan yang berpotensi atau sebagai pewarna alami di kota Metro dapat dilihat pada tabel berikut di bawah ini :

Tabel 2. Inventarisasi, Nama Ilmiah, Manfaat dan Distribusi tumbuhan yang berpotensi atau sebagai pewarna alami di kota Metro Tahun 2014

\begin{tabular}{|c|c|c|c|c|c|c|c|}
\hline No. & $\begin{array}{l}\text { Nama } \\
\text { Lokal }\end{array}$ & Nama Ilmiah & Famili & Habitus & $\begin{array}{l}\text { Bagian } \\
\text { yang } \\
\text { manfaat }\end{array}$ & $\begin{array}{l}\text { Warna } \\
\text { yang } \\
\text { dihasilkan }\end{array}$ & $\begin{array}{l}\text { Lokasi } \\
\text { ditemukan }\end{array}$ \\
\hline 1. & Anggur & Vitis vinifera $\mathrm{L}$. & Vitaceae & liana & buah & Anggur & $\begin{array}{l}\text { metro } \\
\text { selatan }\end{array}$ \\
\hline 2. & Aren & $\begin{array}{l}\text { Arenga pinnata } \\
\text { Merr }\end{array}$ & Arecaceae & pohon & Gula jawa & Coklat & $\begin{array}{l}\text { Metro } \\
\text { Timur dan } \\
\text { selatan }\end{array}$ \\
\hline 3. & Asoka & Ixora pudica Baker & Rubiaceae & herba & $\begin{array}{l}\text { Buah dan } \\
\text { bunga }\end{array}$ & $\begin{array}{l}\text { Merah } \\
\text { hitam }\end{array}$ & $\begin{array}{l}\text { Di Seluruh } \\
\text { Kota Metro }\end{array}$ \\
\hline 4. & $\begin{array}{l}\text { Bawang } \\
\text { Merah }\end{array}$ & Allium cepa & Amaryllidaceae & herba & umbi & Coklat & $\begin{array}{l}\text { Metro } \\
\text { Utara }\end{array}$ \\
\hline 5 . & $\begin{array}{l}\text { Bawang } \\
\text { Sebrang }\end{array}$ & $\begin{array}{l}\text { Eleutherine } \\
\text { palmifolia Merr. }\end{array}$ & Amaryllidaceae & herba & Umbi & $\begin{array}{l}\text { Merah } \\
\text { kecoklat an }\end{array}$ & $\begin{array}{l}\text { Metro } \\
\text { Selatan }\end{array}$ \\
\hline 6. & $\begin{array}{l}\text { Blimbing } \\
\text { Wulung }\end{array}$ & Averrhoa bilimbi & Oxalidaceae & pohon & bunga & Merah & $\begin{array}{l}\text { Metro } \\
\text { Pusat } \\
\end{array}$ \\
\hline 7. & Bougenvil & $\begin{array}{l}\text { Bougainvillea } \\
\text { glabra }\end{array}$ & Nyctaginaceae & perdu & bunga & $\begin{array}{l}\text { Merah } \\
\text { muda }\end{array}$ & $\begin{array}{l}\text { Di Seluruh } \\
\text { Kota Metro }\end{array}$ \\
\hline 8. & $\begin{array}{l}\text { Bunga } \\
\text { Sepatu }\end{array}$ & $\begin{array}{l}\text { Hibiscus rosa- } \\
\text { chinensis L. }\end{array}$ & Malvaceae & Perdu & bunga & Ungu & $\begin{array}{l}\text { metro timur } \\
\text { dan utara }\end{array}$ \\
\hline 9. & $\begin{array}{l}\text { Bunga } \\
\text { Tahi } \\
\text { Kotok }\end{array}$ & Tagetes erecta & Asteraceae & herba & bunga & Kuning & $\begin{array}{l}\text { Metro } \\
\text { Barat, } \\
\text { Metro } \\
\text { Selatan }\end{array}$ \\
\hline 10. & $\begin{array}{l}\text { Bunga } \\
\text { Tembeleka } \\
\mathrm{n}\end{array}$ & Lantana camara $\mathrm{L}$. & Verbenaceae & herba & bunga & Kuning & $\begin{array}{l}\text { Di Seluruh } \\
\text { Kota Metro }\end{array}$ \\
\hline 11. & Buah naga & $\begin{array}{l}\text { Hylocereus undatus } \\
\text { (Haw.)Britt.Et R }\end{array}$ & Cactaceae & Herba & Buah & Ungu & $\begin{array}{l}\text { Di Seluruh } \\
\text { Kota Metro }\end{array}$ \\
\hline 12. & Cabe & Capsicum annum $\mathrm{L}$ & Solanaceae & herba & buah & Merah & Di Seluruh \\
\hline
\end{tabular}


RASUANE N. , PENYUSUNAN LEMBAR KERJA

\begin{tabular}{|c|c|c|c|c|c|c|c|}
\hline & Merah & & & & & & Kota Metro \\
\hline 13. & Coklat & Theobroma cacao L. & Malvaceae & pohon & Biji Buah & Cokelat & $\begin{array}{l}\text { Di Seluruh } \\
\text { Kota Metro }\end{array}$ \\
\hline 14. & Ganyong & Canna sp. & Cannaceae & herba & bunga & $\begin{array}{l}\text { Merah } \\
\text { kehitaman }\end{array}$ & $\begin{array}{l}\text { Metro } \\
\text { Barat }\end{array}$ \\
\hline 15. & $\begin{array}{l}\text { Ganyong } \\
\text { Hias }\end{array}$ & Canna indica $\mathrm{L}$. & Cannaceae & herba & bunga & $\begin{array}{l}\text { Merah } \\
\text { kehitaman }\end{array}$ & $\begin{array}{l}\text { Di Seluruh } \\
\text { Kota Metro }\end{array}$ \\
\hline 16. & $\begin{array}{l}\text { Harendong } \\
\text { Bulu }\end{array}$ & $\begin{array}{l}\text { Melastoma affine D. } \\
\text { Don }\end{array}$ & Melastomat aceae & Pohon & $\begin{array}{l}\text { Akar, } \\
\text { buah dan } \\
\text { daun }\end{array}$ & $\begin{array}{l}\text { Merah. } \\
\text { Hitam dan } \\
\text { lembayung }\end{array}$ & $\begin{array}{l}\text { Di Seluruh } \\
\text { Kota Metro }\end{array}$ \\
\hline 17. & $\begin{array}{l}\text { Jambu } \\
\text { Monyet }\end{array}$ & $\begin{array}{l}\text { Anacardium } \\
\text { occidentale } \mathrm{L} \text {. }\end{array}$ & Anacardiaceae & pohon & $\begin{array}{l}\text { Daun dan } \\
\text { buah }\end{array}$ & $\begin{array}{l}\text { Kuning dan } \\
\text { Hitam }\end{array}$ & $\begin{array}{l}\text { Di Seluruh } \\
\text { Kota Metro }\end{array}$ \\
\hline 18. & Jati & Tectona grandis $\mathrm{L}$. & Verbenaceae & pohon & $\begin{array}{l}\text { Kulit akar } \\
\text { dan daun }\end{array}$ & $\begin{array}{l}\text { Merah } \\
\text { kecoklat an }\end{array}$ & $\begin{array}{l}\text { Di Seluruh } \\
\text { Kota Metro }\end{array}$ \\
\hline 19. & Jengkol & $\begin{array}{l}\text { Archidendron } \\
\text { pauciflonm Benth }\end{array}$ & Fabaceae & pohon & Kulit buah & Cokelat & $\begin{array}{l}\text { Di Seluruh } \\
\text { Kota Metro }\end{array}$ \\
\hline 20. & Katuk & $\begin{array}{l}\text { Sauropus } \\
\text { androgynus L. Merr }\end{array}$ & Euphorbiaceae & perdu & Daun & Hijau & $\begin{array}{l}\text { Di Seluruh } \\
\text { Kota Metro }\end{array}$ \\
\hline 21. & $\begin{array}{l}\text { Kelapa } \\
\text { Gading }\end{array}$ & $\begin{array}{l}\text { Cocos } \\
\text { nucifera var. ebume } \\
\text { a }\end{array}$ & Arecaceae & Pohon & $\begin{array}{l}\text { Kulit } \\
\text { sarabut } \\
\text { buah }\end{array}$ & Hijau & $\begin{array}{l}\text { Di Seluruh } \\
\text { Kota Metro }\end{array}$ \\
\hline 22. & Kelapa & Cocos nucifera $\mathrm{L}$ & Arecaceae & Pohon & $\begin{array}{l}\text { Kulit } \\
\text { sarabut } \\
\text { buah }\end{array}$ & Hijau & $\begin{array}{l}\text { Di Seluruh } \\
\text { Kota Metro }\end{array}$ \\
\hline 23. & Kenikir & Cosmos caudatus & Asteraceae & perdu & daun & Kuning & $\begin{array}{l}\text { Di Seluruh } \\
\text { Kota Metro }\end{array}$ \\
\hline 24. & $\begin{array}{l}\text { Kesumba } \\
\text { Keling }\end{array}$ & Bixa orellana $\mathrm{L}$. & Bixaceae & Pohon & buah & Orange & $\begin{array}{l}\text { Metro } \\
\text { Barat }\end{array}$ \\
\hline 25. & Ketapang & Terminalia catappa & combretaceae & pohon & buah & Hijau & $\begin{array}{l}\text { Di Seluruh } \\
\text { Kota Metro }\end{array}$ \\
\hline 26. & $\begin{array}{l}\text { Ketepeng } \\
\text { Cina }\end{array}$ & Cassia alata $\mathrm{L}$. & Fabaceae & pohon & $\begin{array}{l}\text { Bunga } \\
\text { dan daun }\end{array}$ & $\begin{array}{l}\text { Hijau dan } \\
\text { kekuningan }\end{array}$ & $\begin{array}{l}\text { Di Seluruh } \\
\text { Kota Metro }\end{array}$ \\
\hline 27. & Kopi & Coffea rabusta & Rubiaceae & pohon & buah & Hitam & $\begin{array}{l}\text { Metro } \\
\text { Barat }\end{array}$ \\
\hline 28. & Kunyit & $\begin{array}{l}\text { Curcuma domestica } \\
\text { Val. }\end{array}$ & Zingiberaceae & Herba & rimpang & Kuning & $\begin{array}{l}\text { Di Seluruh } \\
\text { Kota Metro }\end{array}$ \\
\hline 29. & Mahoni & Swietenia mahagoni & Meliaceae & Pohon & $\begin{array}{l}\text { Batang } \\
\text { dan daun }\end{array}$ & Cokelat & $\begin{array}{l}\text { Di Seluruh } \\
\text { Kota Metro }\end{array}$ \\
\hline 30. & Mangga & Mangifera indica $\mathrm{L}$. & Anacardiaceae & pohon & $\begin{array}{l}\text { Kulit } \\
\text { batang } \\
\text { dan daun }\end{array}$ & $\begin{array}{l}\text { Hijau dan } \\
\text { kuning }\end{array}$ & $\begin{array}{l}\text { Di Seluruh } \\
\text { Kota Metro }\end{array}$ \\
\hline 31. & Mengkudu & Morinda citrifolia $\mathrm{L}$. & Rubiaceae & pohon & Kulit akar & Merah & $\begin{array}{l}\text { Di Seluruh } \\
\text { Kot a Metro }\end{array}$ \\
\hline 32. & Murbei & Morus alba L. & Moraceae & pohon & Buah & Blue berry & $\begin{array}{l}\text { Metro } \\
\text { Selatan }\end{array}$ \\
\hline 33. & Nanas & $\begin{array}{l}\text { Ananas } \\
\text { comosus } \text { Merr }\end{array}$ & Bromeliaceae & herba & Buah & Kuning & $\begin{array}{l}\text { Metro } \\
\text { Selatan } \\
\end{array}$ \\
\hline 34. & Nangka & $\begin{array}{l}\text { Artocarpus integra } \\
\text { (Thunb.) Merr }\end{array}$ & Moraceae & pohon & Batang & Kuning & $\begin{array}{l}\text { Di Seluruh } \\
\text { Kota Metro }\end{array}$ \\
\hline 35. & Pacar Air & $\begin{array}{l}\text { Impatiens balsamina } \\
\mathrm{L}\end{array}$ & Balsaminacae & perdu & Daun & Merah & $\begin{array}{l}\text { Di Seluruh } \\
\text { Kota Metro }\end{array}$ \\
\hline 36. & $\begin{array}{l}\text { Pacar } \\
\text { Kuku }\end{array}$ & Lawsonia inemis $\mathrm{L}$. & Lythraceae & pohon & Daun & Merah & $\begin{array}{l}\text { Metro } \\
\text { Timur } \\
\end{array}$ \\
\hline 37. & $\begin{array}{l}\text { Pandan } \\
\text { Wangi }\end{array}$ & $\begin{array}{l}\text { Pandanus } \\
\text { ammaryllifolius }\end{array}$ & Pandanaceae & Perdu & Daun & Hijau & $\begin{array}{l}\text { Di Seluruh } \\
\text { Kota Metro }\end{array}$ \\
\hline 38. & Pinang & Areca catech $u \mathrm{~L}$. & Arecaceae & Pohon & Buah & $\begin{array}{l}\text { Coklat } \\
\text { merah } \\
\text { kehitaman }\end{array}$ & $\begin{array}{l}\text { Metro } \\
\text { Timur }\end{array}$ \\
\hline 39. & Puring & $\begin{array}{l}\text { Codiaeum } \\
\text { variegatum } \mathrm{Bi} .\end{array}$ & Euphorbiaceae & Herba & Daun & Ungu & $\begin{array}{l}\text { Di Seluruh } \\
\text { Kota Metro }\end{array}$ \\
\hline 40. & Putri Malu & Mimosa pudica $\mathrm{L}$. & Mimosaceae & Perdu & $\begin{array}{l}\text { Bunga } \\
\text { dan daun }\end{array}$ & $\begin{array}{l}\text { Kuning dan } \\
\text { kehijauan }\end{array}$ & $\begin{array}{l}\text { Di Seluruh } \\
\text { Kota Metro }\end{array}$ \\
\hline 41. & Rambutan & $\begin{array}{l}\text { Nephelium } \\
\text { lappaceum } \mathrm{L} .\end{array}$ & sapindaceae & Pohon & $\begin{array}{l}\text { Daun dan } \\
\text { buah } \\
\text { muda }\end{array}$ & Kuning & $\begin{array}{l}\text { Di Seluruh } \\
\text { Kota Metro }\end{array}$ \\
\hline 42. & Randu & $\begin{array}{l}\text { Ceiba pentandra } \\
\text { (L.) Gaertn. }\end{array}$ & Malvaceae & Pohon & daun & Abu abu & $\begin{array}{l}\text { Di Seluruh } \\
\text { Kota Metro }\end{array}$ \\
\hline 43. & Rosela & $\begin{array}{l}\text { Hibiscus sabdariffa } \\
\text { L. }\end{array}$ & Malvaceae & Herba & Kulit buah & Merah & $\begin{array}{l}\text { Metro } \\
\text { Utara,Selat } \\
\text { an,Barat,Ti } \\
\text { mur }\end{array}$ \\
\hline
\end{tabular}


RASUANE N. , PENYUSUNAN LEMBAR KERJA .....

\begin{tabular}{|c|c|c|c|c|c|c|c|}
\hline 44. & Senggani & $\begin{array}{l}\text { Melastoma } \\
\text { candidum D. }\end{array}$ & Melastomat aceae & Herba & $\begin{array}{l}\text { Bunga } \\
\text { dan bauh }\end{array}$ & Ungu & $\begin{array}{l}\text { metro utara } \\
\text { dan selatan }\end{array}$ \\
\hline 45. & Sirih & Piper betle $\mathrm{L}$. & Piperaceae & Perdu & $\begin{array}{l}\text { Daun dan } \\
\text { buah }\end{array}$ & Merah & $\begin{array}{l}\text { Metro } \\
\text { Barat }\end{array}$ \\
\hline 46. & $\begin{array}{l}\text { Sirih } \\
\text { Merah }\end{array}$ & Piperomatum & Piperaceae & Perdu & $\begin{array}{l}\text { Daun dan } \\
\text { buah }\end{array}$ & Merah & $\begin{array}{l}\text { Metro } \\
\text { Utara }\end{array}$ \\
\hline 47. & Sri Gading & $\begin{array}{l}\text { Dracaena } \\
\text { fragrans var.massa } \\
\text { ngeana }\end{array}$ & Dracaenaceae & Pohon & Bunga & $\begin{array}{l}\text { Kuning } \\
\text { keemasan }\end{array}$ & $\begin{array}{l}\text { Di Seluruh } \\
\text { Kota Metro }\end{array}$ \\
\hline 48. & Suji & $\begin{array}{l}\text { Pleomele } \\
\text { angustifolia N.E.Bro } \\
\text { wn }\end{array}$ & Annonaceae & Pohon & daun & Hijau & $\begin{array}{l}\text { Di Seluruh } \\
\text { Kota Metro }\end{array}$ \\
\hline 49. & Tebu & $\begin{array}{l}\text { Sacchanum } \\
\text { Offcinarum L. }\end{array}$ & Poaceae & Herba & karamel & $\begin{array}{l}\text { Coklat } \\
\text { kehitaman }\end{array}$ & $\begin{array}{l}\text { Metro } \\
\text { Utara,Selat } \\
\text { an,Barat,Ti } \\
\text { mur }\end{array}$ \\
\hline 50. & Teh & $\begin{array}{l}\text { Camellia } \\
\text { sinensis (L.) O.K }\end{array}$ & Theaceae & Herba & daun & Ungu & $\begin{array}{l}\text { Metro } \\
\text { Selatan, } \\
\text { dan Barat }\end{array}$ \\
\hline 51. & Tomat & $\begin{array}{l}\text { Lycopersicum } \\
\text { esculentum }\end{array}$ & Solanaceae & Herba & buah & Orange & $\begin{array}{l}\text { Di Seluruh } \\
\text { Kota Metro }\end{array}$ \\
\hline 52. & Ubi Jalar & $\begin{array}{l}\text { Ipomoea } \\
\text { batatas Poir }\end{array}$ & Convolvulaceae & Perdu & umbi & Ungu & $\begin{array}{l}\text { Di Seluruh } \\
\text { Kota Metro }\end{array}$ \\
\hline
\end{tabular}

Tabe13. Tabulasi Data Hasil Validasi terhadap Desain LKPD

\begin{tabular}{|l|l|c|c|c|}
\hline \multirow{2}{*}{ No } & \multicolumn{1}{|c|}{ Pernyataan } & \multicolumn{2}{|c|}{ Skor } & $\begin{array}{c}\text { Persentase } \\
\text { Kelayakan } \\
\text { (\%) }\end{array}$ \\
\hline 1 & Vover LKPD terlihat jelas, dan menarik. & V2 & 4 & 80 \\
\hline 2 & $\begin{array}{l}\text { Gambar sudah sesuai dengan materi yang } \\
\text { disampaikan. }\end{array}$ & 4 & 4 & 80 \\
\hline 3 & $\begin{array}{l}\text { Penempatan tabel, kolom informasi atau tugas } \\
\text { dalam LKPD sudah tepat. }\end{array}$ & 3 & 4 & 70 \\
\hline 4 & $\begin{array}{l}\text { Ukuran dan jenis huruf pada LKPD terlihat jelas } \\
\text { dan konsisten }\end{array}$ & 4 & 4 & 80 \\
\hline 5 & $\begin{array}{l}\text { Tampilan LKPD tiap halaman menarik dan } \\
\text { konsisten }\end{array}$ & 4 & 4 & 70 \\
\hline 6 & $\begin{array}{l}\text { Ukuran kertas LKPD sudah sesuai standar yang } \\
\text { digunakan yaitu A4 }\end{array}$ & 4 & 5 & 90 \\
\hline 7 & $\begin{array}{l}\text { Pemilihan kata dari setiap informasi mudah } \\
\text { dipahami sesuai dengan perkembangan peserta } \\
\text { didik }\end{array}$ & 4 & 4 & 80 \\
\hline 8 & $\begin{array}{l}\text { Pemilihan kata yang digunakan tidak } \\
\text { mengandung makna yang ambigu }\end{array}$ & 4 & 4 & 80 \\
\hline 9 & $\begin{array}{l}\text { Pemilihan gambar menarik dan sesuai dengan } \\
\text { materi yang disampaikan }\end{array}$ & 4 & 5 & 90 \\
\hline 10 & $\begin{array}{l}\text { Penggunaan warna pada LKPD baik pada tulisan } \\
\text { maupun gambar terlihat jelas, sehingga } \\
\text { menjadikan LKPD terlihat indah dan menarik. }\end{array}$ & 4 & 4 & 80 \\
\hline & $\begin{array}{l}|c| \\
\text { Rata-rata persentase kelayakan (\%) }\end{array}$ \\
\hline
\end{tabular}

Tabe14. Tabulasi Data Hasil Validasi terhadap Materi LKPD

\begin{tabular}{|c|c|c|c|c|}
\hline \multirow{2}{*}{ No } & \multirow{2}{*}{ Pernyataan } & \multicolumn{2}{|c|}{ Skor } & \multirow{2}{*}{$\begin{array}{c}\text { Persentase } \\
\text { Kelayakan } \\
(\%)\end{array}$} \\
\hline & & V1 & V2 & \\
\hline
\end{tabular}




\begin{tabular}{|l|l|l|l|c|}
\hline & $\begin{array}{l}\text { Materi yang dijelaskan sesuai dengan } \\
\text { Kompetensi Inti (KI) dan Kompetensi Dasar } \\
\text { (KD). }\end{array}$ & 4 & 4 & 80 \\
\hline & $\begin{array}{l}\text { Materi yang dijelaskan cukup dalam, dan } \\
\text { mampu memberikan informasi yang baik kepada } \\
\text { siswa tentang materi Jamur Basidiomycota }\end{array}$ & 4 & 4 & 80 \\
\hline 3 & Materi yang disampaikan sudah baik & 4 & 5 & 90 \\
\hline 4 & Sistematika penyusunan materiberurutan & 4 & 4 & 80 \\
\hline 5 & $\begin{array}{l}\text { Penggunaan simbol dan istilah dalam materi } \\
\text { konsisten dan tepat. }\end{array}$ & 4 & 4 & 80 \\
\hline 6 & $\begin{array}{l}\text { Penyusunan kalimat dalam LKPD baik sesuai } \\
\text { dengan ejaan yang disempurnakan (EYD) }\end{array}$ & 4 & 4 & 80 \\
\hline & $\begin{array}{l}\text { Isi LKPD komunikatif, mampu mengajak peserta } \\
\text { didik untuk aktif, dan komunikasi dua arah } \\
\text { terjalin }\end{array}$ & 3 & 4 & 70 \\
\hline 8 & $\begin{array}{l}\text { Materi yang disampaikan sudah mencakup, } \\
\text { fakta, konsep, prinsip, dan prosedur. }\end{array}$ & 5 & 4 & 90 \\
\hline 9 & $\begin{array}{l}\text { Penggunaan bahasa pada isi materi sesuai } \\
\text { dengan perkembangan siswa. }\end{array}$ & 4 & 4 & 80 \\
\hline 10 & $\begin{array}{l}\text { Setiap kegiatan atau soal yang terdapat dalam } \\
\text { LKPD sudah sesuai dengan isi. }\end{array}$ & 3 & 4 & 70 \\
\hline \multicolumn{5}{|l}{ Rata-rata persentase kelayakan (\%) } \\
\hline
\end{tabular}

\section{PEMBAHASAN}

Pewarna alami merupakan suatu zat warna tertentu yang dapat digunakan untuk mewarnai, biasanya pewarna alam yang biasa digunakan sebagai pewarna makanan, tekstil, dan mewarnai benda-benda kerajinan masyarakat, selain itu pewarna alami digunakan untuk mewarnai suatu preparat tertentu. Masyarakat pada umumnya menanam tumbuhan dan menggunakan pewarna alam sebagai pewarna makanan. Adapaun bagian bagian yang digunakan meliputi akar, batang, daun dan bunga. Biasanya pewarna alami ini dapat diperoleh dari tumbuhan yang memiliki warna cerah sehingga dapat digunakan untuk proses pewarnaan suatu tertentu. Warna-warna dihasilkan sesuai dengan kandungan kimia dari hasilkan oleh tumbuhan tersebut seperti contoh zat antosianin yang merupakan kelompok pigmen yang berwarna merah sampai biru. Buah Naga merah (Hylocereus costaricensis Britt. Et R) ini memiliki zat antosianin pada daging buahnya maupun pada kulit buahnya. Handayani dan Rahmawati (2012).

Invertarisasi tumbuhan pewarna alami sangat penting untuk dipelajari selain menambah pengetahuan keaneragaman hayati disekitar kita juga potensi pemanfaatan pewarna alami dalam pembelajaran salah satunya dapat menjadi sebagai pewarna alami dalam kegiatan praktikum di sekolah atau di Laboratorium. Berdasarkan pendapat Wismaji dkk (2010) pewarna alternatif yang dapat digunakan pada kegiatan praktikum pengamatan jaringan tumbuhan mempunyai afinitas yang tinggi terhadap komponen sel jaringan. Pada dasarnya bahan-bahan pewarna alam tersebut dapat diperoleh pada 
lingkungan sekitar dan dapat digunakan sebagai pe warna alternatif yang lebih murah dan tidak berbahaya bagi tubuh.

Berkaitan dengan penelitian tentang Inventarisasi tumbuhan pewarna alami yang ada di Kota Metro, sumber belajar tidak hanya terpaku pada Inventarisasi tumbuhan pewarna alami yang ada di Kota Metro namun hasil penelitiannya juga dapat dijadikan sebagai rancangan sumber belajar. Terutama untuk para siswa di Kota Metro. Menurut Halimah (2008) lingkungan sebagai sumber belajar yang tidak habis-habisnya dalam memberikan pengetahuan kepada peserta didik. Semakin digali semakin banyak yang didapatkan oleh peserta didik. Selain itu lingkungan sebagai sumber belajar ilmiah menyediakan bahanbahan yang tidak usah dibeli, misalnya udara, cahaya matahari, pepohonon, air, rerumputan, dan sebagainya.

Hasil penelitian tentang inventarisasi tumbuhan pewarna alami yang ada di Kota Metro dapat dijadikan sumber belajar berupa LKPD (Lembar Kegiatan Peserta Didik). Pembuatan sumber belajar LKPD mengacu pada materi keanekaragaman hayati. LKPD memuat tujuan pembelajaran, materi pembelajaran, dan lembar kegiatan praktikum peserta didik. Lembar kegiatan praktikum diberikan dalam LKPD memiliki tujuan agar peserta didik tidak hanya memiliki pengetahuan tentang materi saja, namun diharapkan lebih mampu memahami materi dengan adanya keterampilan proses sains pada peserta didik.

Menurut (Maknun, 2012) keterampilan proses sains dapat meletakan dasar logika untuk meningkatkan kemampuan berpikir peserta didik. Peserta didik lebih banyak menggunakan keterampilan proses sains yang mudah yakni pengamatan dan komunikasi, namun seiring perkembangannya peserta didik dapat menggunakan keterampilan proses sains yang lebih kompleks seperti inferensi dan prediksi.

Agar tercipta keterampilan proses sains menerapkan kurikulum 2013 yakni pendekatan ilmiah (Scientific Approach) di pembelajaran maka pembuatan sumber belajar LKPD dengan topik keanekaragaman hayati memuat aspek-aspek keterampilan sains di dalam materi seperti mengamati, menanya, mengasosiasikan, mengkomunikasikan dan membuat jejaring. Tercapainya tujuan pembelajaran dilihat dari penilaian tentang pengetahuan (kognitif), penilaian sikap (afektif) dan keterampilan (psikomotor). Kelayakan sumber belajar LKPD keanekaragaman hayati untuk digunakan sebagai sumber belajar peserta didik SMA/MA dinilai oleh dua validator dengan angket uji ahli terhadap desain dan peyajian materi LKPD. Berdasarkan hasil validasi menunjukan bahwa penyajian materi dan desain LKPD yang masingmasing dinilai menggunakan angket dengan 10 pernyataan mendapatkan skor dengan rentan 3-5 yang menunjukan persentase kelayakan 70\%-90\%. Fahrucah dan Sugiarto (2012) menyatakan secara toritis hasil validasi LKPD memiliki beberapa kriteria yang didasarkan pada persentase hasil validasi. Persentase 0\%-20\% memiliki kriteria sangat kurang, $21 \%-40 \%$ memiliki kriteria kurang, 41-60\% memiliki kriteria cukup, $61 \%-80 \%$ memiliki kriteria kuat, dan $81 \%-100 \%$ 
memiliki kriteria kelayakan sangat kuat.

Hasil penilaian angket uji ahli terhadap penyajian materi dan desain lembar kegiatan peserta didik (LKPD) masing-masing memiliki nilai rata-rata presentasi kelayakan sebesar 80\%. Hasil presentasi tersebut menunjukan bahwa lembar kegiatan peserta didik secara teoritis bernilai kuat dan dapat digunakan sebagai sumber belajar biologi sekolah menengah atas (SMA) dan sederajat.

Kurikulum pembelajaran yang diterapkan di negara Indonesia saat ini adalah kurikulum 2013. Kurikulum ini menekankan seorang guru mampu mengelola pembelajaran yang bermutu sehingga dapat menyajikan pembelajaran yang menarik, kreatif, menantang, dan menyenangkan bagi siswa. Pembelajaran yang disajikan guru akan menarik bukan serta merta karena strategi pembelajaran yang bagus, namun sumber belajar juga memiliki peran yang sangat besar dalam mewujudkan ketercapaian pembelajaran. Upaya yang dapat dilakukan untuk memperbaiki pemahaman dan kemampuan berpikir siswa yaitu dengan diciptakannya suatu sumber belajar yang mendukung upaya perbaikan tersebut. Berdasarkan pernyataan Sanaky (2011), Widyantini (2013), dan Prastowo (2012) dapat disimpulkan bahwa LKPD merupakan salah satu sumber belajar peserta didik yang didesain untuk memudahkan kegiatan belajar peserta didik. LKPD sendiri disusun menggunakan beberapa kriteria yang tujuannya yaitu untuk menarik siswa agar lebih aktif dalam proses pembelajaran. Penyusunan LKPD dapat meliputi beberapa unsur yang harus ada didalamnya.Penggunaan unsur-unsur tersebut tergantung dari pengembang yang akan menggunakannya seperti judul, kompetensi dasar, informasi pendukung, tugas atau langkah kerja, dan penilaian.

\section{KESIMPULAN}

1. Spesies tumbuhan yang berpotensi atau sebagai pewarna alami di kota Metro sebanyak 52 spesies yang ditanam tersebar di berbagai kecamatan.

2. Masyarakat pada umumnya menanam tumbuhan dan menggunakan pewarna alam sebagai pewarna makanan. Adapun bagian yang digunakan meliputi akar, batang, daun dan bunga. Biasanya pewarna alami ini dapat diperoleh dari tumbuhan yang memiliki warna cerah dan khas dari tumbuhan tersebut

3. Hasil penelitian tentang tumbuhan yang berpotensi atau sebagai pewarna alami di kota Metro disusun sebagai rancangan sumber belajar LKPD (Lembar Kerja Peserta Didik) biologi SMA yang berbasis pendekatan ilmiah (Scientific Approach) dan berdasarkan validasi menyatakan bahwa LKPD secara teoritis memiliki kriteria kuat dan dapat digunakan sebagai sumber belajar biologi materi keanekaragaman hayati.

\section{SARAN}

1. Perlu diadakan penelitian tumbuhan yang berpotensi atau sebagai pewarna alami terhadap pewarnaan sel menggantikan pewarna sentetis.

2. Perlu dilakukan penelitian pegembangan sumber belajar 
LKPD (Lembar Kerja Peserta Didik) biologi SMA yang berbasis pendekatan ilmiah (Scientific Approach) sampel yang lebih luas.

\section{DAFTAR RUJUKAN}

Arikunto, S. 2010. Prosedur Penelitian Suatu Pendekatan Praktik. Yogyakarta: Rineka Cipta.

Fahrucah, E. dan B. Sugiarto. 2012. Pengembangan Lembar Kerja Siswa pada Pembelajaran Kimia SMA Kelas XI Pokok Bahasan Faktor-Faktor yang Mempengaruhi Laju Reaksi Melalui Pendekatan Scaffolding. Unesa Journal of Chemical Education. Vol.1, No.1, pp.92-96 Mei 2012. ISSN: 2252-9454.

Handayani, P. A dan A. Rahmawati. 2012. Pemanfaatan Kulit Buah Naga Sebagai Pewarna Alami Makanan Pengganti Pewarna Sintesis. Jurnal Bahan Alam Terbarukan Vol 1 No 2.

Halimah, L. 2008. Pemberdayaan Lingkungan sebagai Sumber Belajar dalam Upaya Meningkatkan Kompetensi Berbahasa Indonesia Siswa Kelas 4 SD Laboratorium UPI Kampus Cibiru. Jurnal Pendidikan Dasar. Nomor 10.

Indrawan, M., R. B. Primack, \& J Supriatna. 2007. Biologi Konservasi. Jakarta: Yayasan Obor Indonesia.

Karwono dan Mularsih. 2012. Belajar dan Pembelajaran. Jakarta : PT Raja Grafindo Persada.

Maknun, D., H. K. S.R. R Hertien, A Munandar, \& S. Subahar. Keterampilan Esensial dan Kompetensi Motorik Laboratorium Mahasiswa
Calon Guru Biologi dalam Kegiatan Praktikum Ekologi. Jurnal Pendidikan IPA Indonesia. Vol 1. No 2. Hal. 141-148

Prastowo, A. 2012. Panduan Kreatif Membuat Bahan Ajar Inovatif. Yogyakarta: DIVA Press.

Puspitadewi, S. (2014). Profil Lks Materi Perubahan Lingkungan Berorientasi Kurikulum 2013 Untuk Melatihkan Berpikir Kritis Siswa. BioEdu. Vol. $3(2): 352-357$

Sanaky, H. 2011. Media Pembelajaran. Yogyakarta: Kaukaba.

Sunaryo. 2002. Psikologi Untuk Keperawatan. Jakarta: Penerbit Buku Kedokteran EGC.

Widyantini, T. 2013. Penyusunan Lembar Kegiatan Siswa (LKS) sebagai Bahan Ajar. Pusat Pengembangan dan Pemberdayaan Pendidik dan Tenaga Kependidikan (PPPPTK) Matematika. Yogyakarta: $\quad$ PPPPTK Matematika.

Wismaji, G., E. Winingsih., dan C. A Noor. 2010. Pemanfaatan Pewarna Alam Nabati sebagai Agen Pewarna Alternatif untuk Pengamatan Mikroskopis Jaringan Tumbuhan. Program Kreatifitas Mahasiswa. 